Article

\title{
Sustainable, Low Flammability, Mechanically-Strong Poly(vinyl alcohol) Aerogels
}

\author{
Zhihan Cheng *(D), Kimberly DeGracia and David A. Schiraldi * \\ Department of Macromolecular Science \& Engineering, Case Western Reserve University, \\ Cleveland, OH 44106-7202, USA; kcd21@case.edu \\ * Correspondence: zxc357@case.edu (Z.C.); das44@case.edu (D.A.S.); Tel.: +01-216-338-4243
}

Received: 24 September 2018; Accepted: 2 October 2018; Published: 5 October 2018

check for updates

\begin{abstract}
Poly(vinyl alcohol) (PVA), tannic acid (TA) and sodium hydroxide ( $\mathrm{NaOH}$ ) were used to prepare low-flammability, mechanically-strong aerogels via an environmentally-friendly freeze-drying method. Because of the strong interaction between TA and PVA through hydrogen bonds, PVA/TA/NaOH aerogels exhibited compressive moduli as high as $12.7 \mathrm{MPa}, 20$ times that of the control PVA aerogel. The microstructure of the aerogels in this study showed that the addition of $\mathrm{NaOH}$ disrupted the typical "card of house" aerogel structure, while the samples with TA showed a stereoscopic uniform structure. The thermal stabilities of aerogels were tested by thermogravimetric analysis, showing both a decrease on the onset of decomposition temperature, and a reduction in decomposition rate after initial char formation. The peak heat release rate and total heat release, as measured by cone calorimetry, dropped by $69 \%$ and $54 \%$, respectively, after adding TA and $\mathrm{NaOH}$.
\end{abstract}

Keywords: aerogels; poly(vinyl alcohol); flammability; tannic acid

\section{Introduction}

Aerogels were first described by Kistler in 1931 utilizing a novel sol-gel and drying process [1]. This family of materials typically exhibit bulk densities ranging from 0.005 to $0.1 \mathrm{~g} / \mathrm{cm}^{3}$ [2-4], and have attracted a great deal of attention because of their low densities, high specific surface areas, high porosities (and abilities to serve as absorbents) and low thermal conductivities. In thermal insulation, liquid absorbents, energy storage, catalyst supports, and supercapacitors have all been reported [5-10]. Beyond the use of silica, aerogels have also been demonstrated based upon clay, graphene, carbon nanotubes and polymers [6,11-13]. Poly(vinyl alcohol) (PVA), as a hydrophilic and water soluble polymer, is an ideal candidate for fabricating polymer aerogels because of its low toxicity, good chemical stability, and favorable mechanical properties [14]. Such PVA aerogels can be prepared using a sustainable, freeze-drying method [15]. Different methods have been reported with which to enhance the properties of PVA aerogels, including multiple freeze-thaw processes [16], radiation treatment [17-19], and addition of crosslinking agents [20] or incorporation of cellulose nanofibrils into the polymer [21]. Enhancements of mechanical properties have been demonstrated using the above methods, but few of these reduce the flammability of the aerogels, which are otherwise comparable to polymer foams. High flame retardancy PVA aerogels are ideal candidates to replace foams in the area of building materials and consumer products [16]. Incorporation of flame retardants, such as ammonium polyphosphate, potassium carbonate and silica gel reduced PVA aerogel flammability but at the cost of reducing mechanical properties [22,23].

Tannic acid (TA) is a naturally-occurring substance, which serves as a flame retardant when concentrated in the bark of trees, providing thermal and microbial protection [24,25]. TA (Figure 1) contains a central core of polyhydric alcohols connected to gallic acid through ester linkages. This structure lends itself to decomposition into graphite, making it a potential char-forming 
additive [26]. TA is considered to be sustainable and nontoxic, as opposed to traditional phosphorous-or halogen -based flame retardants, such as organophosphates, polybrominated biphenyls (PBBs) and polybrominated diphenyl ethers (PBDEs) [27]. TA can hydrogen bond with PVA through its many phenolic groups, potentially increasing the polymer aerogel's mechanical properties. In order to provide an effective char layer when added to PVA, the concentration of TA cannot be too low (TA:PVA $>20 \%$ ); when the concentration of PVA exceeds ratio over the limit $(20 \%)$, a coagulation can occur in PVA solutions which hinders aerogel production $[28,29]$. Sodium hydroxide can be added to the polymer/TA mixtures to adjust $\mathrm{pH}$ and increase the solubility of the desired component $[30,31], \mathrm{NaOH}$ also has the function of catalyzing char formed from TA, because sodium cations could catalyze the dehydration of matrix, which contributes to the char layer [32]. To the best of our knowledge, there is no similar system reported in the literature. In the present work, $\mathrm{TA}$ and $\mathrm{NaOH}$ were incorporated into the PVA aerogel system to provide flame retardancy and improve mechanical properties. The resultant mechanical properties, morphologies, thermal stabilities, and combustion behaviors were investigated.

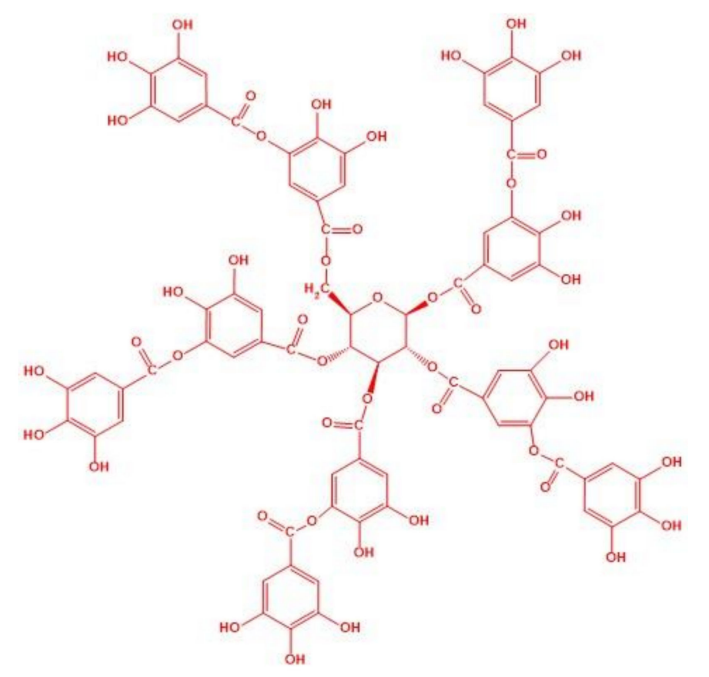

Figure 1. The structure of tannic acid.

\section{Experimental Section}

\subsection{Materials}

Poly(vinyl alcohol) (PVA; $\mathrm{M}_{\mathrm{w}}$ 13,000-23,000; 98\% hydrolyzed), tannic acid (Sigma-Aldrich, St. Louis, MO, USA) and sodium hydroxide (pellets) (Aldon Corp, Rochester, NY, USA) were used without further purification. Deionized (DI) water was obtained using a Barnstead RoPure low-pressure, reverse-osmosis system (Lake Balboa, CA, USA).

\subsection{Preparation of Aerogels}

PVA solutions were prepared by stirring PVA powder with DI water for six hours at $90^{\circ} \mathrm{C}$. Sodium hydroxide and TA were mixed together with DI water under magnetic stirring for $30 \mathrm{~min}$ before addition into the PVA solutions. Compositions without tannic acid were prepared in the same manner as the aerogels containing TA; the solutions were mixed to the desired PVA concentrations at $50{ }^{\circ} \mathrm{C}$ until they were homogeneous suspensions. The suspensions were poured into $12.5 \mathrm{ml}$ polystyrene vials (for compression testing) or cast into a $100 \mathrm{~mm} \times 100 \mathrm{~mm} \times 10 \mathrm{~mm}$ rectangular mold (for cone calorimetry testing) and frozen in a solid carbon dioxide/ethanol bath $\left(-70^{\circ} \mathrm{C}\right)$. These samples were freeze dried using a VirTis Advantage EL-85 lyophilizer, with the shelf temperature set to $25^{\circ} \mathrm{C}$, and the pressure set to under $10 \mu \mathrm{bar}$. The products are referred to as $\mathrm{Px} / \mathrm{Ty} / \mathrm{S}$, where $\mathrm{P}$ represents PVA, T represents tannic acid and $S$ represents sodium hydroxide; the subscripts indicate their content 
per $100 \mathrm{ml}$ water. The amount of sodium hydroxide used was based on the amount of TA: for $1 \%$ TA, $0.587 \mathrm{~g}$ (the amount is calculated according to Equation (1)) sodium hydroxide is added in the solution. For the composition with sodium hydroxide without TA, the amount of sodium hydroxide was added as $0.587 \mathrm{wt} \%$. All compositions are shown in Table 1 . The samples were stored in a desiccator after fabrication and were dried in a vacuum oven at $50{ }^{\circ} \mathrm{C}$ before characterization.

$$
m_{\mathrm{NaOH}}=1 * \frac{25}{M_{\mathrm{TA}}} * \mathrm{M}_{\mathrm{NaOH}}
$$

Table 1. Composition of aerogels.

\begin{tabular}{ccccc}
\hline Sample & PVA (g/\%total) & Tannic acid (g/\%total) & NaOH (g/\%total) & DI water (g) \\
\hline P5 & $5 / 100 \%$ & $0 / 0 \%$ & $0 / 0 \%$ & 100 \\
P10 & $10 / 100 \%$ & $0 / 0 \%$ & $0 / 0 \%$ & 100 \\
P5/S & $5 / 90 \%$ & $0 / 0 \%$ & $0.587 / 10 \%$ & 100 \\
P5/T1/S & $5 / 76 \%$ & $1 / 15 \%$ & $0.587 / 9 \%$ & 100 \\
P5/T2/S & $5 / 61 \%$ & $2 / 25 \%$ & $1.174 / 14 \%$ & 100 \\
\hline
\end{tabular}

\subsection{Characterizations}

The aerogel densities were calculated by measuring the mass and dimensions using a Mettler Toledo AB204-S analytical balance (Greifensee, Switzerland) and a digital caliper (Fisher Scientific, Pittsburgh, PA, USA). Every composition was tested with five samples.

The compression test was conducted on Instron model 5500 universal testing machine (Instron, Norwood, MA, USA ), fitted with a $1 \mathrm{KN}$ load cell and $10 \mathrm{~mm} / \mathrm{min}$ compression rate. The modulus was attained from the slope of the area under the linear portion of the stress-strain curve. Five cylindrical samples ( $20 \mathrm{~mm}$ in diameter and height) were tested for each composition, and the results were averaged.

Scanning electron microscopy (SEM) was conducted on a HITACHI S-4500 scanning electron microscope (Hitachi, Tokyo, Japan) at an acceleration voltage of $5 \mathrm{kV}$. Each sample was fractured in liquid nitrogen, then sputter coated with a $10 \mathrm{~nm}$ platinum layer on the surface for observing.

The thermal properties were measured by thermogravimetric analysis (TGA), using TGA Q550 (TA Instruments, New Castle, PA, USA). The specimens were placed on a platinum pan, equilibrated at $100{ }^{\circ} \mathrm{C}$ for $3 \mathrm{~min}$, then heated to $700{ }^{\circ} \mathrm{C}$ at a speed of $10^{\circ} \mathrm{C} / \mathrm{min}$. The process was conducted under a nitrogen flow rate of $40 \mathrm{~mL} / \mathrm{min}$.

The combustion behavior of the aerogel was measured using a cone calorimeter (Fire Testing Technology, East Grinstead, UK) in accordance with the ASTM E 1354 standard. The heat flux was set to $50 \mathrm{~kW} / \mathrm{m}^{2}$. The rectangular samples $(100 \mathrm{~mm} \times 100 \mathrm{~mm} \times 10 \mathrm{~mm})$ were wrapped with aluminum foil before testing.

\section{Results and Discussion}

\subsection{Mechanical Properties}

Table 2 lists the densities and compressive moduli for the samples produced in this study. The aerogels containing sodium hydroxide and tannic acid showed shrinkage after freeze drying while maintaining their shapes in the mold. The P5 aerogel has the lowest shrinkage and the lowest solid concentration, and thus showed the lowest density. The sample densities increased with increasing solids content, as would be expected.

Due to its large number of hydroxyl groups resulting in extensive hydrogen bonding, TA would be expected to serve as a crosslinking agent in PVA aerogels [28,29,33].

The addition of sodium hydroxide would be expected to partially deprotonate the PVA, reducing interchain hydrogen bonding, but densifying the aerogels due to higher overall levels of solids. 
The base would more extensively deprotonate phenolic and carboxylic acid groups on the tannic acid backbone, setting up a complex ionic structure. The base plus tannic acid combination not only increased the moduli of the PVA aerogels, but also their specific moduli (Figure 2), correcting for the higher total solids and higher bulk densities of these materials.

Table 2. Densities and compression properties of PVA aerogels, $\mathrm{PVA} / \mathrm{NaOH}$ aerogel and PVA/TA/NaOH.

\begin{tabular}{cccc}
\hline Sample & Density $\left(\mathbf{g} / \mathbf{c m}^{3}\right)$ & Modulus $(\mathbf{M P a})$ & Specific modulus $\left(\mathbf{M P a ~ c m}^{\mathbf{3}} / \mathbf{g}\right)$ \\
\hline P5 & $0.065 \pm 0.003$ & $0.5 \pm 0.0$ & $7.7 \pm 0.4$ \\
P10 & $0.124 \pm 0.002$ & $8.6 \pm 2.3$ & $69 \pm 18$ \\
P5/S & $0.087 \pm 0.001$ & $1.4 \pm 0.4$ & $16 \pm 5$ \\
P5/T1/S & $0.088 \pm 0.001$ & $4.3 \pm 0.6$ & $49 \pm 7$ \\
P5/T2/S & $0.141 \pm 0.003$ & $13 \pm 3$ & $90 \pm 21$ \\
\hline
\end{tabular}

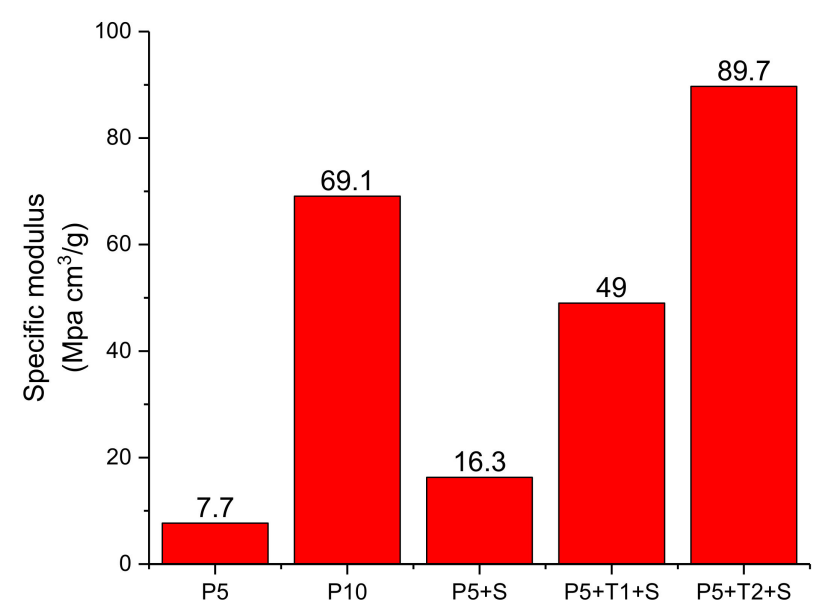

Figure 2. Specific moduli of aerogels with different content.

\subsection{Morphology}

SEM was used to study the structure of aerogels and interrelationship between different compositions. As shown in Figure 3A,B, unmodified PVA aerogels exhibit lamellar (house of cards) structures typical of such materials [34]. Aerogels produced containing sodium hydroxide Figure 3C,D lack this normal structure, suggesting that interactions with the freezing water and polymer are different than in the neutral systems, disrupting the lamellar ice formation. With the addition of TA into the formulation, a more uniform, dendritic morphology was observed Figure $3 \mathrm{E}, \mathrm{F}$; the sodium hydroxide would be expected to preferentially deprotonate acidic groups on the TA, allowing for increased hydrogen bonding to the PVA, and normal hydration (and ice formation upon freezing) of the polymer/TA complex.

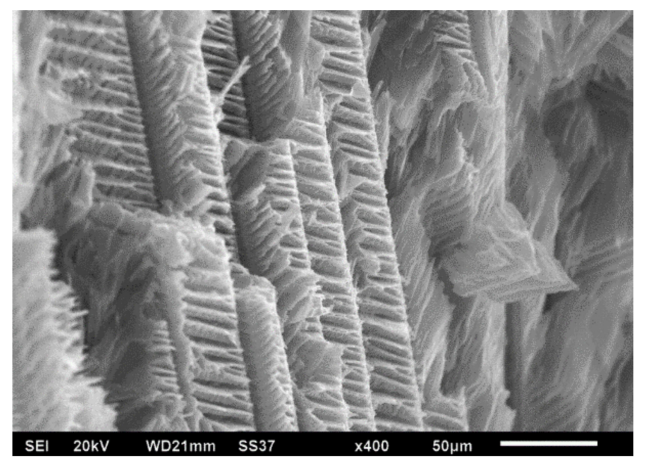

(A)

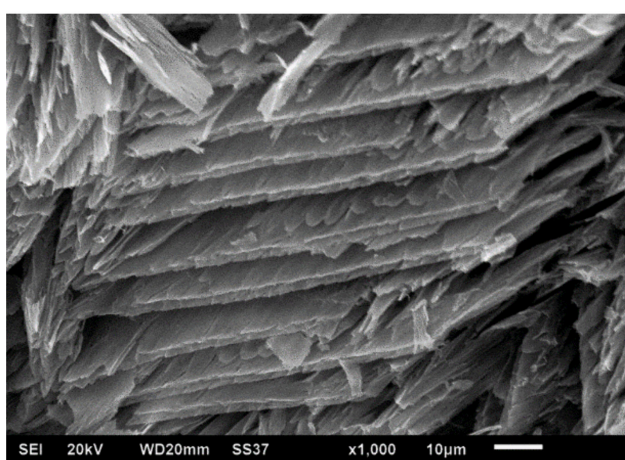

(B)

Figure 3. Cont. 


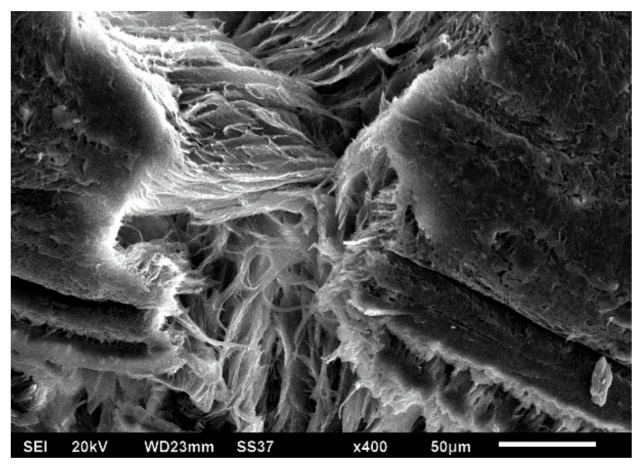

(C)

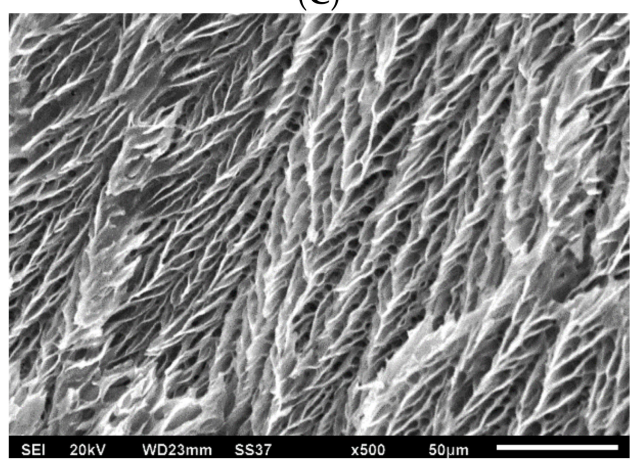

(E)

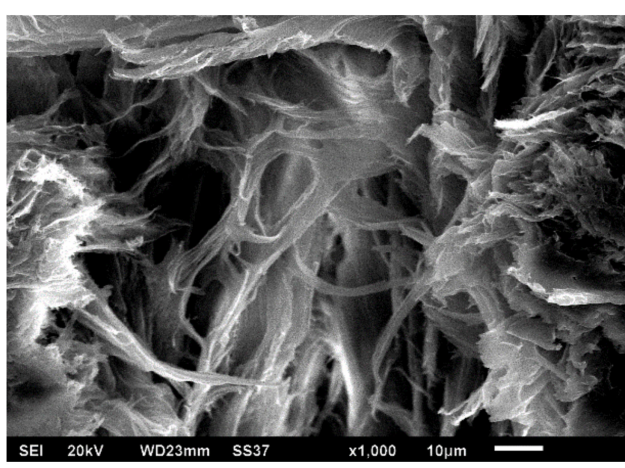

(D)

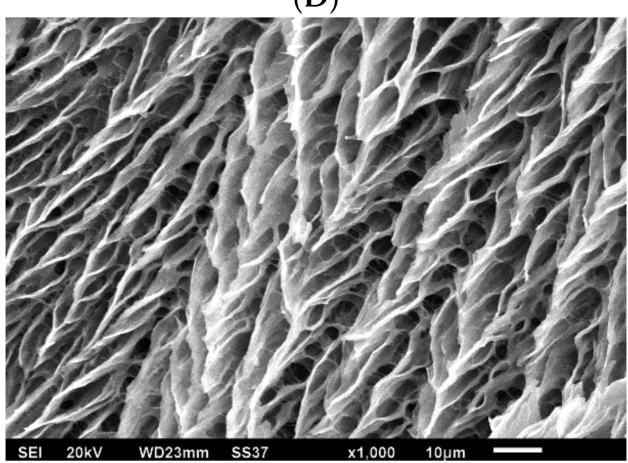

(F)

Figure 3. SEM images of aerogel samples. (A,B) P5; (C,D) P5/S, (E,F) P5/T2/S.

\subsection{Thermal Stability}

The thermal stabilities of the aerogels in this study were investigated by thermogravimetric analysis (TGA; Figure 4) and differential thermogravimetry (DTG; Figure 5). The data are summarized in Table 3, which includes the decomposition temperatures at $10 \%$ weight $\operatorname{loss}\left(T_{\mathrm{d} 10 \%}\right)$, at $20 \%$ weight loss $\left(T_{\mathrm{d} 20 \%}\right)$, and at the maximum decomposition rates $\left(T_{\mathrm{dmax}}\right)$, the values at maximum mass decomposition rate $(\mathrm{dW} / \mathrm{dT})$ and the residue. PVA aerogels are hydrophilic and could easily absorb water. To avoid the influence of moisture, the samples were heated to $100{ }^{\circ} \mathrm{C}$ at a heating rate of $40^{\circ} \mathrm{C} / \mathrm{min}$ from room temperature and then equilibrated at $100{ }^{\circ} \mathrm{C}$ for $3 \mathrm{~min}$ and then ramped to $700{ }^{\circ} \mathrm{C}$ at a heating rate of $10^{\circ} \mathrm{C} / \mathrm{min}$ under nitrogen.

The weight losses before $100{ }^{\circ} \mathrm{C}$ were likely the result of water desorption, a common phenomenon in hydrophilic materials. The main decomposition step occurred between $150-500{ }^{\circ} \mathrm{C}$. The onset decomposition was evaluated by $\mathrm{T}_{\mathrm{d} 10 \%}$. With the addition of $\mathrm{TA}$ and $\mathrm{NaOH}$, the onset temperature decreased, likely because of the effect of added sodium hydroxide as previously reported [18,32,35].

The $\mathrm{T}_{\mathrm{d} 10 \%}, \mathrm{~T}_{\mathrm{d} 20 \%}, \mathrm{~T}_{\mathrm{dmax}}$ values of aerogels that incorporated $\mathrm{TA}$ and $\mathrm{NaOH}$ all dropped compared with the pristine PVA aerogel, while the maximum mass-decomposition rates (dW/dT) also dropped from 3.03 to 1.41 and the residue (char yield) increased from $2.6 \%$ to $35 \%$, the corresponding sharp weight-losses are given in Figure 5. These data suggest that a char layer was formed before the bulk decomposition of the PVA matrix. This char layer could hamper the heat transfer and therefore mitigated the decomposition of PVA; this is consistent with Figure 4, which shows that the sharp weight losses were prevented by the formation of char. Both TA and $\mathrm{NaOH}$ exhibited positive effects on increasing the formation of char [32]. For the samples with TA, this high level of char was most likely formed from TA, a known precursor to graphite. For samples with only $\mathrm{NaOH}$, the char formation argues that basic conditions/deprotonation of the polymer hinders the normal thermal degradation mechanism present with this material, allowing a carbonization pathway to occur first. Such a pathway could involve hydrogen atom transfers to produce unsaturated polymer backbones, ultimately leading to unsaturated rings. The nature of this mechanism will be the subject of a future study. With increasing TA levels, more of this known char former will be available, leading to a more robust layer, a $10 \%$ 
decrease of maximum mass-decomposition rates, and a $40 \%$ increase in the residue. Though the onset of the decomposition temperature dropped caused by the addition of $\mathrm{NaOH}$, the addition of TA and sodium hydroxide further suppressed the weight loss during the main degradation; this effect is greatly dependent upon the concentration of $\mathrm{TA}$, not $\mathrm{NaOH}$, as reported [32]. The decomposition temperature was slightly enhanced by adding more TA. This may be because TA can impart better thermal stability.

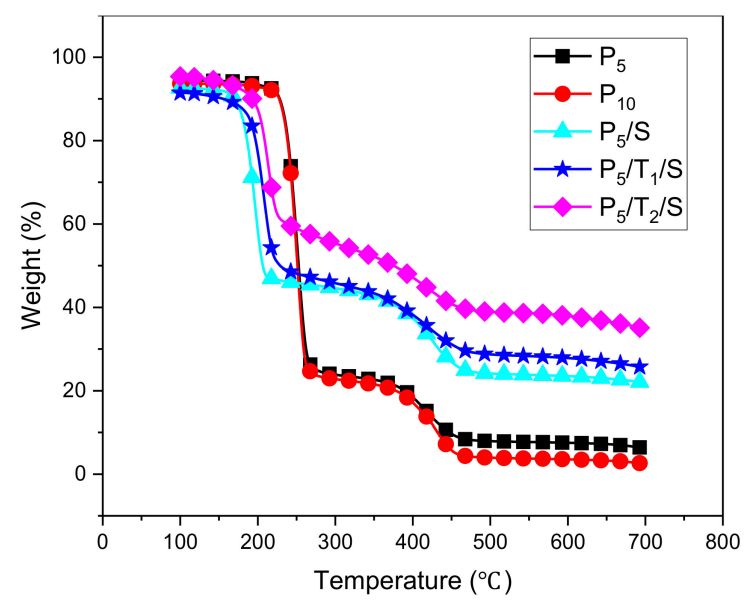

Figure 4. TGA curves of PVA, $\mathrm{PVA} / \mathrm{NaOH}, \mathrm{PVA} / \mathrm{TA} / \mathrm{NaOH}$ aerogels at a heating rate of $10^{\circ} \mathrm{C} / \mathrm{min}$ under nitrogen.

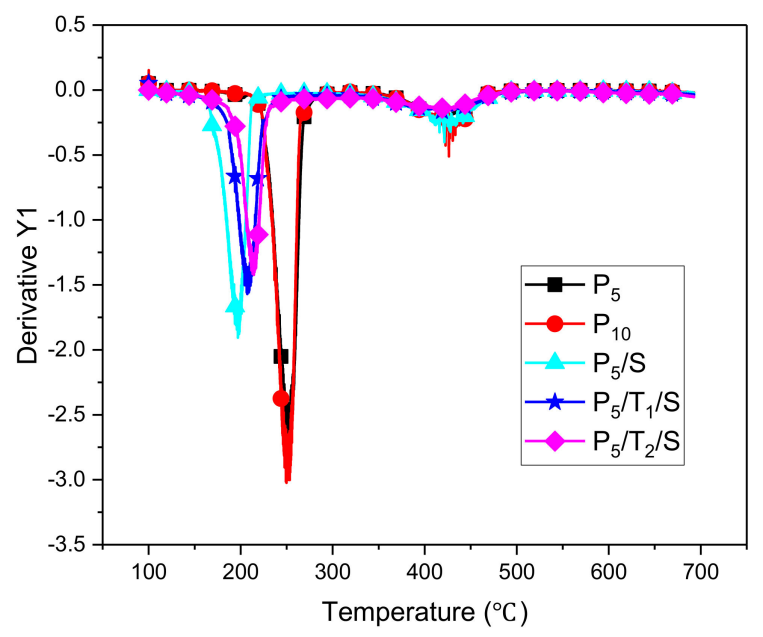

Figure 5. TGA curves of PVA, $\mathrm{PVA} / \mathrm{NaOH}, \mathrm{PVA} / \mathrm{TA} / \mathrm{NaOH}$ aerogels at a heating rate of $10^{\circ} \mathrm{C} / \mathrm{min}$ under nitrogen.

Table 3. TGA data of freeze dried PVA, $\mathrm{PVA} / \mathrm{NaOH}, \mathrm{PVA} / \mathrm{TA} / \mathrm{NaOH}$ aerogels.

\begin{tabular}{ccccccc}
\hline Sample & $\operatorname{Td} 10 \%\left({ }^{\circ} \mathbf{C}\right)$ & $\operatorname{Td20} \%\left({ }^{\circ} \mathbf{C}\right)$ & $\operatorname{Tdmax}\left({ }^{\circ} \mathbf{C}\right)$ & Dw/dt $\left(\% /{ }^{\circ} \mathbf{C}\right)$ & Weight at 100(\%) & Residue (\%) \\
\hline P5 & 228 & 239 & 250 & 2.67 & 94.4 & 6.4 \\
P10 & 228 & 238 & 250 & 3.03 & 93.6 & 2.6 \\
P5/S & 170 & 186 & 198 & 1.88 & 92.6 & 22 \\
P5/T1/S & 156 & 197 & 208 & 1.57 & 91.4 & 26 \\
P5/T2/S & 193 & 209 & 214 & 1.41 & 95.4 & 35 \\
\hline
\end{tabular}

\subsection{Combustion Behavior}

The combustion behavior of the aerogels was studied using cone calorimetry (Table 4); the time to ignition (TTI), peak of heat release (PHRR), time to peak of heat release (TTPHRR), the fire growth rates (FIGRA) and total heat release (THR) were compared for the samples. 
Table 4. Cone calorimeter data of PVA, $\mathrm{PVA} / \mathrm{NaOH}, \mathrm{PVA} / \mathrm{TA} / \mathrm{NaOH}$ aerogels.

\begin{tabular}{|c|c|c|c|c|c|c|c|}
\hline Sample & $\begin{array}{l}\text { Weight } \\
\text { (g) }\end{array}$ & $\begin{array}{l}\text { TTI } \\
\text { (s) }\end{array}$ & $\begin{array}{c}\text { PHRR } \\
\left(\mathrm{kW} / \mathrm{m}^{2}\right)\end{array}$ & $\begin{array}{l}\text { TTPHRR } \\
\text { (s) }\end{array}$ & $\begin{array}{c}\text { FIGRA } \\
\left(\mathrm{kW} /\left(\mathrm{s} \mathrm{m}^{2}\right)\right)\end{array}$ & $\begin{array}{c}\text { THR } \\
\left(\mathrm{MJ} / \mathrm{m}^{2}\right)\end{array}$ & $\begin{array}{l}\text { THR/mass } \\
\left(\mathrm{MJ} /\left(\mathrm{m}^{2} \mathrm{~g}\right)\right)\end{array}$ \\
\hline P5 & 5.3 & 8 & 534 & 32 & 16.7 & 12.9 & 2.4 \\
\hline P10 & 8.9 & 8 & 574 & 51 & 11.3 & 21.1 & 2.4 \\
\hline $\mathrm{P} 5 / \mathrm{S}$ & 5.9 & 3 & 160 & 12 & 13.4 & 9.4 & 1.6 \\
\hline $\mathrm{P} 5 / \mathrm{T} 1 / \mathrm{S}$ & 5.8 & 6 & 201 & 16 & 12.6 & 8.3 & 1.4 \\
\hline $\mathrm{P} 5 / \mathrm{T} 2 / \mathrm{S}$ & 6.7 & 7 & 166 & 37 & 4.5 & 7.5 & 1.1 \\
\hline
\end{tabular}

Although the samples containing TA or $\mathrm{NaOH}$ ignited easily under the heat flux of $50 \mathrm{~kW} / \mathrm{m}^{2}$, their overall flammability was significantly reduced. The heat release rate (HRR) plot is given in Figure 6; the control PVA aerogels showed a sharp peak, while the samples containing TA showed a relatively broad doublet peak in the HRR plot. The shape of samples with TA and $\mathrm{NaOH}$ is a typical HRR curve of thick charring materials. The PHRR of the PVA aerogels was approximately $550 \mathrm{~kW} / \mathrm{m}^{2}$; with the increase in the concentration of TA, the PHRR dropped continuously and the PHRR of P5/T2/S dropped to $166 \mathrm{~kW} / \mathrm{m}^{2}$, which was about $31 \%$ of the number for pure PVA aerogel. Because of the rupture of the char during combustion, the plots of aerogels with TA showed two HRR peaks [36].

Figure 7 and Table 4 presents the THR curves of the aerogels of this study. Control PVA samples exhibited a much higher THR than aerogels that incorporated TA and $\mathrm{NaOH}$. To eliminate the influence of mass differences, THR/mass was compared so it could better illustrate the combustion behavior of the sample. The P5/T2/S aerogel exhibited the lowest THR/mass value, which was $1.1 \mathrm{MJ} /\left(\mathrm{m}^{2} \cdot \mathrm{g}\right)$, $46 \%$ of the primitive PVA aerogels.

FIGRA data are given in Table 4. Lower FIGRA values indicate that the material has a lower flammability. Aerogels containing $\mathrm{TA}$ and $\mathrm{NaOH}$ showed a significant decrease in FIGRA and aerogels with higher TA concentration exhibited lower FIGRA. For the P5/T2/S aerogel, the value dropped from about 17 to $5 \mathrm{MJ} / \mathrm{m}^{2}$. The addition of large amounts of TA will decrease the fire growth rate significantly.

The data above all showed that the addition of TA and $\mathrm{NaOH}$ will decrease the flammability of materials. The materials containing TA and $\mathrm{NaOH}$ ignited earlier than pure PVA aerogels, apparently forming char rapidly, before the full matrix polymer could ignite. Aerogels with higher concentrations of $\mathrm{TA}$ and $\mathrm{NaOH}$ formed a denser char layer, which protected the matrix better from the heat and the flammable gas. TA releases 1,2,3-benzene triol and carbon dioxide as major gaseous products resulting from the decarboxylation in its outer layer of gallic acid units [26]. Sodium hydroxide could potentially facilitate decarboxylation of tannic acid at lower temperatures, which enhanced the formation of intumescent char, consistent with the flame retardancy observed with this system [32]. The aerogel modified with only $\mathrm{NaOH}$ also ignited rapidly, suggesting a base-catalyzed degradation of PVA which produced carbon precursors; these aerogels also formed char layer during combustion tests, consistent with their low PHRR and FIGRA compared to unmodified PVA aerogel. The char layer may form because the $\mathrm{NaOH}$ can produce high-carbon-content structures via deprotonation and the release of other small molecular substances during the combustion. We speculate that the deprotonated (or at least base-coordinated alcohol) may enhance beta-scission reaction, creating carbon-carbon double bonds in the polymer backbone, which ultimately could cyclize to produce aromatic char. To the best of our knowledge, this base effect on the flammability of PVA has not been reported but appears to be profound in scope. Development of a detailed mechanism for this effect will be the subject of continuing research by our team. 


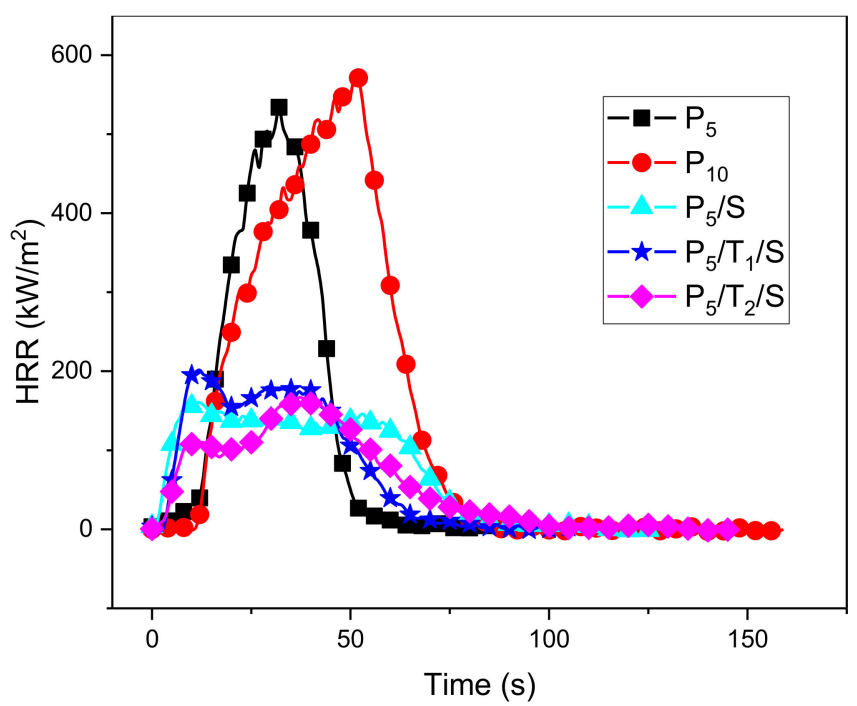

Figure 6. HRR plots of PVA, PVA/NaOH, PVA/TA/NaOH aerogels.

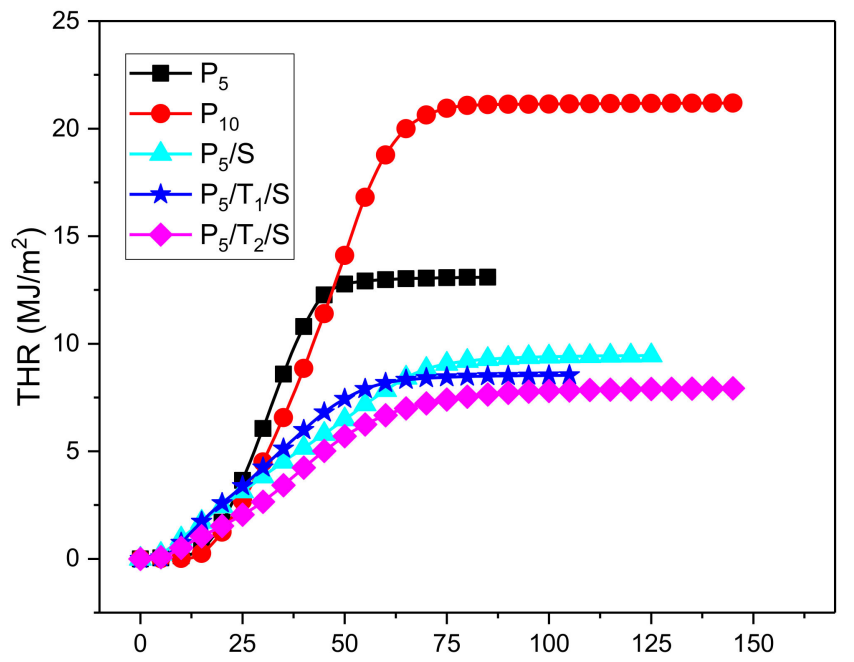

Figure 7. THR plots of PVA, PVA/NaOH, PVA/TA/NaOH aerogels.

\section{Conclusions}

PVA aerogels with TA or TA/NaOH were prepared through a simple and environmentally friendly freeze-drying process. The densities, compressive moduli, morphologies, thermal stabilities and combustion behaviors were all investigated. By adjusting $\mathrm{pH}$, homogeneous solutions of TA could be produced. Aerogels that contained TA enhanced the compressive moduli greatly, compared to control aerogels, likely due to significant hydrogen bonding between TA and PVA. The aerogels containing both $\mathrm{NaOH}$ and TA exhibited the highest compressive moduli, about 24 times the value of the control aerogels. SEM images showed that PVA aerogels containing TA possessed denser structures, consistent with interaction between TA and PVA. The addition of TA and $\mathrm{NaOH}$ decreased the onset decomposition temperature in TGA testing, but the decomposition process of PVA was hindered after the formation of significant char. Combustion tests showed that the PHRR decreased from 534 to $166 \mathrm{~kW} / \mathrm{m}^{2}$ and THR decreased from 12.9 to $7.5 \mathrm{MJ} / \mathrm{m}^{2}$ with the addition of TA and NaOH. The FIGRA also dropped by adding TA and $\mathrm{NaOH}$. The aerogels modified only with $\mathrm{NaOH}$ showed a similar thermal stability and flammability to aerogels containing TA, likely due to an alternative mechanism for the production of char. The results in this study indicate that the addition of the relatively benign additives TA and $\mathrm{NaOH}$ can significantly decrease PVA aerogel flammability, producing a low-density, 
mechanically-strong material which does not require the use of halogens or phosphorous compounds in order to minimize their flammability.

Author Contributions: Conceptualization, D.A.S. and Z.C.; methodology, D.C.; validation, Z.C., formal analysis, Z.C. and D.A.S.; investigation, Z.C. and K.D.; resources, D.A.S.; data curation, Z.C.; writing-original draft preparation, Z.C.; writing-review and editing, D.A.S.; supervision, D.A.S.; project administration, D.A.S.; funding acquisition, D.A.S.

Funding: This research received no external funding.

Conflicts of Interest: The authors declare no conflicts of interest.

\section{References}

1. Kistler, S.S. Coherent Expanded Aerogels and Jellies. Nature 1931, 127, 741. [CrossRef]

2. Bandi, S.; Schiraldi, D.A. Glass Transition Behavior of Clay Aerogel/Poly (Vinyl Alcohol) Composites. Macromolecules 2006, 39, 6537-6545. [CrossRef]

3. Aaltonen, O.; Jauhiainen, O. The Preparation of Lignocellulosic Aerogels from Ionic Liquid Solutions. Carbohydr. Polym. 2009, 75, 125-129. [CrossRef]

4. Zou, J.; Liu, J.; Karakoti, A.S.; Kumar, A.; Joung, D.; Li, Q.; Khondaker, S.I.; Seal, S.; Zhai, L. Ultralight Multiwalled Carbon Nanotube Aerogel. ACS Nano 2010, 4, 7293-7302. [CrossRef] [PubMed]

5. Haq, E.U.; Zaidi, S.F.A.; Zubair, M.; Karim, M.R.A.; Padmanabhan, S.K.; Licciulli, A. Hydrophobic Silica Aerogel Glass-Fibre Composite with Higher Strength and Thermal Insulation Based on Methyltrimethoxysilane (MTMS) Precursor. Energy Build. 2017, 151, 494-500. [CrossRef]

6. Gawryla, M.D.; Schiraldi, D.A. Novel Absorbent Materials Created Via Ice Templating. Macromol. Mater. Eng. 2009, 294, 570-574. [CrossRef]

7. Xia, W.; Qu, C.; Liang, Z.; Zhao, B.; Dai, S.; Qiu, B.; Jiao, Y.; Zhang, Q.; Huang, X.; Guo, W. High-Performance Energy Storage and Conversion Materials Derived from a Single Metal-organic Framework/Graphene Aerogel Composite. Nano Letters 2017, 17, 2788-2795. [CrossRef] [PubMed]

8. Pajonk, G.M. Aerogel Catalysts. Appl. Catal. 1991, 72, 217-266. [CrossRef]

9. Zhang, Y.; Zuo, L.; Huang, Y.; Zhang, L.; Lai, F.; Fan, W.; Liu, T. In-Situ Growth of Few-Layered MoS2 Nanosheets on Highly Porous Carbon Aerogel as Advanced Electrocatalysts for Hydrogen Evolution Reaction. ACS Sustain. Chem. Eng. 2015, 3, 3140-3148. [CrossRef]

10. Yu, Z.; McInnis, M.; Calderon, J.; Seal, S.; Zhai, L.; Thomas, J. Functionalized Graphene Aerogel Composites for High-Performance Asymmetric Supercapacitors. Nano Energy 2015, 11, 611-620. [CrossRef]

11. Arndt, E.M.; Gawryla, M.D.; Schiraldi, D.A. Elastic, Low Density Epoxy/Clay Aerogel Composites. J. Mater. Chem. 2007, 17, 3525-3529. [CrossRef]

12. Xu, Z.; Zhang, Y.; Li, P.; Gao, C. Strong, Conductive, Lightweight, Neat Graphene Aerogel Fibers with Aligned Pores. ACS Nano 2012, 6, 7103-7113. [CrossRef] [PubMed]

13. Ma, C.; Du, B.; Wang, E. Self-Crosslink Method for a Straightforward Synthesis of Poly (Vinyl Alcohol)-Based Aerogel Assisted by Carbon Nanotube. Adv. Funct. Mater. 2017, 27, 1604423. [CrossRef]

14. Chen, H.; Wang, Y.; Schiraldi, D.A. Preparation and Flammability of Poly (Vinyl Alcohol) Composite Aerogels. ACS Appl. Mater. Interfaces 2014, 6, 6790-6796. [CrossRef] [PubMed]

15. Wang, Y.; Zhao, H.; Degracia, K.; Han, L.; Sun, H.; Sun, M.; Wang, Y.; Schiraldi, D.A. Green Approach to Improving the Strength and Flame Retardancy of Poly(Vinyl Alcohol)/Clay Aerogels: Incorporating Biobased Gelatin. ACS Appl. Mater. Interfaces 2017, 9, 42258-42265. [CrossRef] [PubMed]

16. Hickey, A.S.; Peppas, N.A. Mesh Size and Diffusive Characteristics of Semicrystalline Poly (Vinyl Alcohol) Membranes Prepared by Freezing/Thawing Techniques. J. Membr. Sci. 1995, 107, 229-237. [CrossRef]

17. Chen, H.; Hollinger, E.; Wang, Y.; Schiraldi, D.A. Facile Fabrication of Poly (Vinyl Alcohol) Gels and Derivative Aerogels. Polymer 2014, 55, 380-384. [CrossRef]

18. Chen, H.; Liu, B.; Huang, W.; Wang, J.; Zeng, G.; Wu, W.; Schiraldi, D.A. Fabrication and Properties of Irradiation-Cross-Linked Poly (Vinyl Alcohol)/Clay Aerogel Composites. ACS Appl. Mater. Interfaces 2014, 6, 16227-16236. [CrossRef] [PubMed] 
19. Immelman, E.; Bezuidenhout, D.; Sanderson, R.D.; Jacobs, E.P.; van Reenen, A.J. Poly(Vinyl Alcohol) Gel Sub-Layers for Reverse Osmosis Membranes. III. Insolubilization by Crosslinking with Potassium Peroxydisulphate. Desalination 1993, 94, 115-132. [CrossRef]

20. Trochimczuk, A.W.; Kabay, N.; Arda, M.; Streat, M. Stabilization of Solvent Impregnated Resins (SIRs) by Coating with Water Soluble Polymers and Chemical Crosslinking. React. Funct. Polym. 2004, 59, 1-7. [CrossRef]

21. Liu, A.; Medina, L.; Berglund, L.A. High-Strength Nanocomposite Aerogels of Ternary Composition: Poly (Vinyl Alcohol), Clay, and Cellulose Nanofibrils. ACS Appl. Mater. Interfaces 2017, 9, 6453-6461. [CrossRef] [PubMed]

22. Wang, L.; Sanchez-Soto, M.; Maspoch, M.L. Polymer/Clay Aerogel Composites with Flame Retardant Agents: Mechanical, Thermal and Fire Behavior. Mater. Des. 2013, 52, 609-614. [CrossRef]

23. Gilman, J.W.; Ritchie, S.J.; Kashiwagi, T.; Lomakin, S.M. Fire-retardant Additives for Polymeric materials-I. Char Formation from Silica Gel-potassium Carbonate. Fire Mater. 1997, 21, 23-32. [CrossRef]

24. Tributsch, H.; Fiechter, S. The Material Strategy of Fire-Resistant Tree Barks. High Performance Structures and Materials IV. WIT Trans. Built Environ. 2008, 97, 43-52.

25. Cowan, M.M. Plant Products as Antimicrobial Agents. Clin. Microbiol. Rev. 1999, 12, 564-582. [PubMed]

26. Xia, Z.; Singh, A.; Kiratitanavit, W.; Mosurkal, R.; Kumar, J.; Nagarajan, R. Unraveling the Mechanism of Thermal and Thermo-Oxidative Degradation of Tannic Acid. Thermochim. Acta 2015, 605, 77-85. [CrossRef]

27. Darnerud, P.O. Toxic Effects of Brominated Flame Retardants in Man and in Wildlife. Environ. Int. 2003, 29, 841-853. [CrossRef]

28. Chen, Y.; Peng, L.; Liu, T.; Wang, Y.; Shi, S.; Wang, H. Poly (Vinyl Alcohol)-tannic Acid Hydrogels with Excellent Mechanical Properties and Shape Memory Behaviors. ACS Appl. Mater. Interfaces 2016, 8, 27199-27206. [CrossRef] [PubMed]

29. Hong, K.H. Polyvinyl Alcohol/Tannic Acid Hydrogel Prepared by a Freeze-Thawing Process for Wound Dressing Applications. Polym. Bull. 2017, 74, 2861-2872. [CrossRef]

30. Alexy, P.; Kachova, D.; Kršiak, M.; Bakoš, D.; Šimková, B. Poly (Vinyl Alcohol) Stabilisation in Thermoplastic Processing. Polym. Degrad. Stab. 2002, 78, 413-421. [CrossRef]

31. Chu, W.; Yang, J.; Liu, T.; Tiu, C.; Guo, J. The Effects of pH, Molecular Weight and Degree of Hydrolysis of Poly (Vinyl Alcohol) on Slot Die Coating of PVA Suspensions of TiO2 and SiO2. Colloids Surf. Physicochem. Eng. Aspects 2007, 302, 1-10. [CrossRef]

32. Nam, S.; Condon, B.D.; Xia, Z.; Nagarajan, R.; Hinchliffe, D.J.; Madison, C.A. Intumescent Flame-Retardant Cotton Produced by Tannic Acid and Sodium Hydroxide. J. Anal. Appl. Pyrolysis 2017, 126, 239-246. [CrossRef]

33. Shi, S.; Peng, X.; Liu, T.; Chen, Y.; He, C.; Wang, H. Facile Preparation of Hydrogen-Bonded Supramolecular Polyvinyl Alcohol-Glycerol Gels with Excellent Thermoplasticity and Mechanical Properties. Polymer 2017, 111, 168-176. [CrossRef]

34. Van Olphen, H. Polyelectrolyte Reinforced Aerogels of Clays-Application as Chromatographic Adsorbents. Clays Clay Miner. 1967, 15, 423-435. [CrossRef]

35. Nam, S.; Kim, H.J.; Condon, B.D.; Hinchliffe, D.J.; Chang, S.; McCarty, J.C.; Madison, C.A. High Resistance to Thermal Decomposition in Brown Cotton is Linked to Tannins and Sodium Content. Cellulose 2016, 23, 1137-1152. [CrossRef]

36. Schartel, B.; Hull, T.R. Development of Fire-retarded Materials-Interpretation of Cone Calorimeter Data. Fire Mater. 2007, 31, 327-354. [CrossRef]

(C) 2018 by the authors. Licensee MDPI, Basel, Switzerland. This article is an open access article distributed under the terms and conditions of the Creative Commons Attribution (CC BY) license (http://creativecommons.org/licenses/by/4.0/). 